\title{
Psychological Features in Patients with Different Patterns of Irritable Bowel Syndrome
}

\author{
Chowdhury SR ${ }^{1}$, Safwath SA $^{2}$, Ghosh DK ${ }^{3}$, Akter F ${ }^{4}$
}

\begin{abstract}
Conflict of Interest: None

Received: 28.04.2019

Accepted: 27.08 .2019

www.banglajol.info/index.php/JSSMC

Context: Irritable bowel syndrome (IBS) is one of the most common chronic gastrointestinal (GI) disorders. Recently, many studies have found the association between irritable bowel syndrome (IBS) \& the psychological factors.

Aims: The study aimed to determine the relationship between psychological features and different subtypes and severity of irritable bowel syndrome.

Settings and Design: This cross-sectional study was performed among 208 outpatients diagnosed as irritable bowel syndrome in two government medical college hospitals of Dhaka city from January, 2015 to December, 2015. The subtypes and severity of irritable bowel syndrome were assessed by Rome-III and 'Irritable bowel syndrome severity scoring scale' respectively. Psychological features were assessed by Brief Symptom Inventory consisting 53 items of psychological problems.
\end{abstract}

\section{Key Words:}

Psychological features, Irritable bowel syndrome
Results: Global severity index of Brief Symptom Inventory, which is the best indicator of psychological distress, was found significantly higher in respondents with diarrhea predominant IBS $(p<0.001)$ and severe IBS patients $(p<0.001)$. Mean scores of other psychological problems among Brief Symptom Inventory -53 subscales (hostility, interpersonal sensitivity, paranoid ideation, psychoticism, depression, anxiety) were significantly higher in diarrhoea predominant $I B S$ and severe IBS patients compared to the others $(p<0.001)$. Severity score of irritable bowel syndrome was also moderately correlated with Global severity index $(r=0.417, p<0.001)$.

Conclusions: This study found relationship between psychological features and different pattern of irritable bowel syndrome. Hence, the appropriate psychological assessment and counseling in IBS patients is critically important.

[J Shaheed Suhrawardy Med Coll 2019; 11(2): 110-114] DOI: https://doi.org/10.3329/jssmc.v11i2.48960

\section{Introduction}

Functional gastrointestinal disorders (FGIDs) are characterized by chronic and recurrent gastrointestinal (GI) symptoms with ambiguous pathophysiology. ${ }^{1}$ Irritable bowel syndrome (IBS) is one of the most common functional gastrointestinal disorders characterized by

1. Dr. Sadia Rahman Chowdhury, Assistant Professor, Department of Community Medicine, Jalalabad Ragib Rabeya Medical College, Sylhet.

2. Dr. Syed Alamgir Safwath, Professor (CC), Department of Gastroenterology, Jalalabad Ragib Rabeya Medical College.

3. Dr. Dilip Kumar Ghosh, Associate Professor, Department of Gastroenterology, Shaheed Suhrawardy Medical College.

4. Dr. Fahmida Akter, Assistant Professor, Department of Epidemiology, NIPSOM.

Correspondence to: Dr. Sadia Rahman Chowdhury, Assistant Professor, Department of Community Medicine, Jalalabad Ragib Rabeya Medical College, Sylhet. Phone:01743322871, E-mail: sadiarahman chowdhury@yahoo.com chronic abdominal pain with altered bowel habits in the absence of any structural, physiological, or biochemical abnormalities in the GI tract. ${ }^{2,3 \& 4}$ It has been estimated that $5 \%-10 \%$ of the adult populations in Asian countries are affected by IBS. ${ }^{5}$ The association between psychiatric disturbance and gastrointestinal (GI) disorders such as Irritable Bowel Syndrome (IBS) is well established ${ }^{6,7}$. IBS is not a psychiatric disorder, but psychosocial factors influence how the illness is experienced and acted upon ${ }^{8}$. Rates of co-morbidity with psychiatric disorders range from $54 \%$ to $94 \%$ in treatment-seeking patient with IBS. ${ }^{9,10}$ Anxiety, depression and somatoform disorders are the most prevalent psychiatric conditions linked to IBS. It is reported that at least one of these disorders is present in approximately $40 \%$ to $60 \%$ of IBS patients visited by physicians in gastroenterology clinics. ${ }^{8}$ 
When comparing the various subtypes of IBS, Farzanehet al. ${ }^{11}$ showed there are no different symptomatic profiles where as Muscatello et al. ${ }^{12}$ found difference in psychological testing between IBS subtypes. A strong correlation can be observed between the severity of IBS and its co-morbid psychiatric disorders, especially depression and anxiety. ${ }^{13,14}$ Hence, the appropriate psychological assessment in these patients is critically important. Modabbernia et al. ${ }^{15}$ suggested in their study that psychiatric assessment may facilitate management of the IBS sufferers and improve their quality-of-life because of the high prevalence of anxiety-depressive disorders and low quality-of-life scores in IBS patients. To our knowledge there are a very few studies evaluated the possible relationship between the subtype and severity of IBS patients and psychiatric symptoms in developing countries. Although a range of studies concerning IBS has been conducted on estimation of the prevalence of IBS, there is little information on the investigation of psychological feature of IBS patients in our country.

\section{Methodology:}

A cross-sectional study was done among purposively selected 208 respondents visited by gastroenterologist from January, 2015 to December, 2015 and diagnosed as irritable bowel syndrome (IBS) at gastroenterology outpatient department of Dhaka Medical College Hospital and Shaheed Suhrawardy Medical College Hospital in Dhaka.

The IBS-SSS is used to measure severity of IBS and according to this severity scoring scale IBS severity is classified into mild, moderate and severe IBS. Francis et al. ${ }^{16}$ examined the reliability and validity of the IBS-SSS. According to the latest version of Rome III diagnostic criteria, the IBS subtypes were constipation predominant IBS (IBS-C), diarrhoea predominant IBS (IBS-D) and mixed type IBS (IBS-M).

Brief Symptom Inventory-53 (BSI-53) scale is used for psychological features which consists of 53-items concerning an individual's psychological problems in the past 7 days and comprising nine primary symptom dimensions (somatization, obsessive-compulsive, interpersonal sensitivity, depression, anxiety, hostility, phobic anxiety, paranoid ideation and psychotics) and global severity index (GSI), which is the single best indicator of current distress levels and should be utilized in most instances where a single summary measure is required ${ }^{13}$. All data were analyzed using SPSS 16.0 software. To see the association Pearson's chi-square test, one-way ANOVA, correlation, independent sample t-test and Multiple Linear regression were done where and whenever required. All the tests were two tailed and $\mathrm{p}<$ 0.05 was considered to be statistically significant.

\section{Result:}

Two hundred and eight irritable bowel syndrome (IBS) patients (77\% males, $23 \%$ females) were enrolled to the study. Mean age of patients under study was 32.3 (+ $10.32)$ years and most of them were educated up to secondary level (35.6\%), married (66.8\%), and skilled and unskilled labour (30\%).

Diarrhea predominant IBS (IBS-D) was the most frequent subtypes of IBS patients seen by gastroenterologist $(50 \%)$, followed by mixed type IBS (IBS-M) (42\%) and constipation predominant IBS (IBS-C) $(8 \%)$. The study also revealed that the mean severity score of IBS patients was $28.21(+7.25)$ and majority of the respondents suffered from moderately severe IBS (53\%) followed by severe IBS (37\%) and mild IBS (10\%). The psychopathological features of the different subtypes and severity of IBS were compared using the Brief Symptom Inventory-53 (BSI53) scale.

As shown in [Table $1 \& 2$ ], diarrhea predominant IBS (IBS-D) and severe IBS patients were more suffered from psychiatric symptoms. There were statistical significant differences between mean scores of IBS-C, IBS-D, and IBS-M patients and between severe IBS, moderately severe IBS and mild IBS patients regarding to global severity index (GSI) scores of BSI-53 scale.

The mean scores of obsessive-compulsive disorder, hostility, interpersonal sensitivity, paranoid ideation, psychoticism, depression, anxiety subscales of Brief Symptom Inventory-53 (BSI-53) were also found higher in IBS-D patients than IBS-C and IBS-M patients and mean scores of somatization, hostility, interpersonal sensitivity, paranoid ideation, psychoticism, depression and anxiety of BSI-53 subscales were found higher in patients with severe IBS than moderately severe and mild IBS. These differences were found statistically significant $(P<0.05)$.

In Multiple Linear regression analysis, the association between IBS subtype and global severity index (GSI) and between IBS severity and GSI remained significant $(\mathrm{p}<$ 0.001 ) after adjusting the effect of age of respondents. 


\section{Table-I}

Comparing mean scores of age and the BSI-53 GSI and subscales among different subtypes of IBS patients

\begin{tabular}{|c|c|c|c|c|}
\hline Variables & $\begin{array}{c}\text { IBS - C } \\
\text { Mean +SD }\end{array}$ & $\begin{array}{c}\text { IBS - D } \\
\text { Mean +SD }\end{array}$ & $\begin{array}{c}\text { IBS - M } \\
\text { Mean + SD }\end{array}$ & $\mathrm{p}$ - value \\
\hline Age & $32.94+10.81$ & $31.59+10.38$ & $32.92+9.91$ & \\
\hline \multicolumn{5}{|l|}{ BSI 9-subscales } \\
\hline Somatization & $0.80+0.31$ & $0.93+0.43$ & $0.81+0.39$ & 0.106 \\
\hline Interpersonal sensitivity & $* 68.03$ & $* 121.68$ & $* 90.83$ & $<0.001$ \\
\hline Depression & $0.48+0.27$ & $0.96+0.57$ & $0.81+0.53$ & 0.002 \\
\hline Anxiety & $0.54+0.38$ & $1.26+0.54$ & $1.0+0.52$ & $<0.001$ \\
\hline Hostility & 62.19 & 121.14 & 92.53 & $<0.001$ \\
\hline Phobic anxiety & 82.28 & 111.78 & 99.93 & 0.111 \\
\hline Paranoid ideation & 69.00 & 115.15 & 98.37 & 0.001 \\
\hline Psychoticism & 61.09 & 113.34 & 101.94 & 0.003 \\
\hline Obsessive compulsive & $0.66+0.51$ & $1.16+0.51$ & $0.80+0.59$ & $<0.001$ \\
\hline \multicolumn{5}{|l|}{ Index } \\
\hline Global severity index (GSI) & $0.37+0.16$ & $0.70+0.28$ & $0.55+0.27$ & $<0.001$ \\
\hline
\end{tabular}

* Mean rank of Kruskal-Wallis test.

Table-II

Comparing mean scores of age and the BSI-53 GSI and subscales among IBS patients with different severity

\begin{tabular}{|c|c|c|c|c|}
\hline Variables & $\begin{array}{c}\text { Mild IBS } \\
\text { Mean +SD }\end{array}$ & $\begin{array}{c}\text { Moderate IBS } \\
\text { Mean +SD }\end{array}$ & $\begin{array}{l}\text { Severe IBS } \\
\text { Mean }+ \text { SD }\end{array}$ & $\mathrm{p}$ - value \\
\hline \multicolumn{5}{|l|}{$\overline{\text { Age }}$} \\
\hline \multicolumn{5}{|l|}{ BSI 9-subscales } \\
\hline Somatization & $0.56+0.31$ & $0.76+0.37$ & $1.12+0.34$ & $<0.001$ \\
\hline Interpersonal sensitivity & $* 72.83$ & $* 98.24$ & $* 122.08$ & \\
\hline Depression & $0.60+0.40$ & $0.73+0.55$ & $1.11+0.49$ & $<0.001$ \\
\hline Anxiety & $0.78+0.42$ & $1.04+0.59$ & $1.26+0.51$ & 0.001 \\
\hline Hostility & 75.10 & 95.74 & 125.04 & $<0.001$ \\
\hline Phobic anxiety & 66.10 & 91.56 & 133.45 & $<0.001$ \\
\hline Paranoid ideation & 78.81 & 101.59 & 115.67 & 0.008 \\
\hline Psychoticism & 51.57 & 100.30 & 124.93 & $<0.001$ \\
\hline Obsessive-compulsive disorder & $0.90+0.44$ & $0.93+0.57$ & $1.06+0.61$ & 0.263 \\
\hline \multicolumn{5}{|l|}{ Index } \\
\hline Global severity index (GSI) & $0.41+0.15$ & $0.55+0.30$ & $0.75+0.24$ & $<0.001$ \\
\hline
\end{tabular}

*Mean rank of Kruskal-Wallis test.

Pearson correlations analysis revealed highly statistically significant moderate correlation between IBS severity score and global severity index of Brief Symptom Inventory $(r=0.417, p<0.001)$. After adjusting the effect of age of respondents, multiple linear regression analysis also showed persistent association between IBS severity score and GSI (F change $=41.74, \mathrm{p}<0.001)$. 


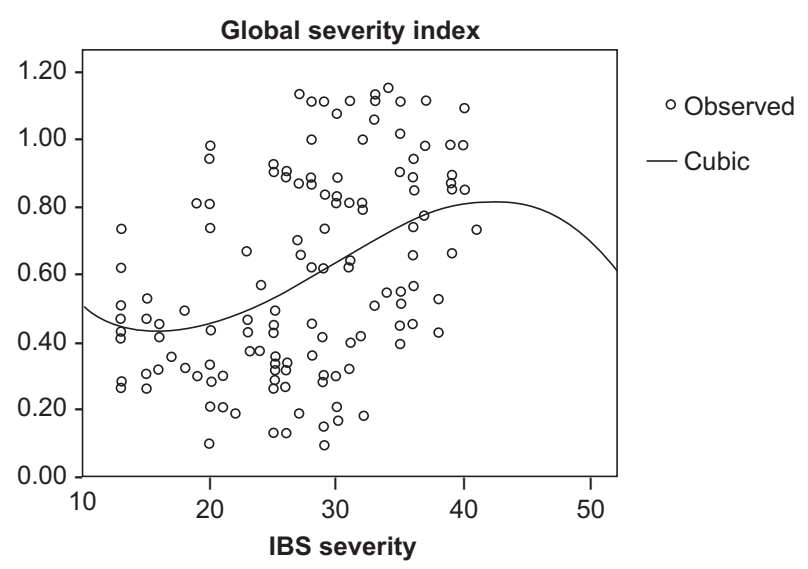

Fig.-1: IBS severity score and global severity index

\section{Discussion:}

This study was conducted to find out the psychological feature in patients diagnosed with irritable bowel syndrome (IBS) in gastroenterology outpatient department. It is found that IBS-D (50\%) was more common subtype of IBS among respondents than IBS-M (42\%) and IBS-C $(8 \%)$. Another study of Bangladesh also found IBS-D as the most prevalent subtype. ${ }^{17}$ The result showed that the majority of the respondents were with moderately severe IBS (53\%) whereas among the rest $37 \%$ were with severe IBS and only $10 \%$ were with mild IBS. It is found that the majority of the IBS cases are moderately severe in a study. ${ }^{18}$

Among the respondents, nine domains of the psychological feature were scored by 9 subscales and global severity index (GSI) according to Brief Symptom Inventory (BSI53). The GSI, the single best indicator of current distress levels of BSI, combines information on the numbers of symptoms and the intensity of perceived distress ${ }^{19}$. This study revealed that there were significant differences between the subtypes of IBS regarding to psychiatric symptoms. The psychiatric scores especially depression, anxiety, interpersonal sensitivity, hostility, paranoid ideation and psychoticism and obsessive -compulsive disorder, statistically higher in the IBS-D $(p<0.05)$ patients in comparison to other subtypes of IBS. This study showed that there were significant differences in mean score of psychological feature (global severity index) between various subtypes of IBS. Respondents with IBS-D had statistically significant higher mean score of global severity index $(0.70+0.28, \mathrm{p}<0.05)$ than those with IBS-M and IBS-C. In line with the present study, another study mentioned psychiatric problems among IBS patients have some relation with type of IBS ${ }^{20}$. Consistent with our study; another study also reported that IBS subtypes have different profiles in psychological symptoms. ${ }^{12}$
The result of current study revealed respondent suffering severe IBS $(p<0.05)$ had statistically significant higher mean score of somatization, interpersonal sensitivity, hostility, paranoid ideation, phobic anxiety and psychoticism depression, anxiety and global severity index (GSI) $(0.75+0.24, p<0.05)$ than those with moderate and mild IBS severity level. The association between IBS severity and GSI remained significant $(\mathrm{p}<0.001)$, after adjusting other variable (age of respondents) in 'Multiple Linear regression analysis'. Similar to this finding, other studies showed that severity of IBS has a significant relation with the presence of anxiety-depressive disorders and depressed patients are suffered more from a severe type of IBS and provided evidence that anxiety is an important mediating factor affecting the GI symptom severity. ${ }^{15,21}$

Global severity index (GSI) score, the best indicator of psychological distress, was found moderately correlated with IBS severity score which was statistically highly significant. No studies so far revealed comparable to this result but other study reported a positive correlation between the GSI and the number of gastrointestinal symptoms in IBS patients. ${ }^{22}$

In this cross-sectional study, assessment of psychological score by Brief Symptom Inventory (BSI) showed significant differences among subtypes regarding psychological features, notably, interpersonal sensitivity, anxiety, paranoid ideation, psychoticism, depression and GSI. Psychological distress scores (somatization, interpersonal sensitivity, paranoid ideation, phobic anxiety, anxiety, depression and psychoticism) was found higher in respondents with severe IBS than other groups and GSI was also found moderately correlated with IBS severity score. Another study also found that psychological features are strongly associated with IBS; notably, interpersonal sensitivity, somatization, paranoid ideation, depression, phobic anxiety, and GSI is significantly associated with IBS. $^{23}$

The study result showed significant differences between subtypes of IBS regarding to psychological features. Also, psychological distress of patients were influenced and significantly correlated with severity of IBS. Thus, the relationship between psychological features and IBS subtypes and severity found in the current study emphasize the importance of the psychological evaluation of the patients with IBS to identify those who might be suffering from psychological disorders in order to better management of the patients and supports a case for screening of psychological disorders in gastroenterology department of hospitals. 


\section{References:}

1. Corazziari E. Definition and epidemiology of functional gastrointestinal disorders. Best Pract Res ClinGastroenterol. 2004; 18(4):613-31.

2. Fan YJ, Chen SJ, Yu YC, et al. A probiotic treatment containing Lactobacillus, Bifidobacterium and Enterococcus improves IBS symptoms in an open label trial. J Zhejiang Univ-Sci B (Biomed \&Biotechnol). 2006; 7(12):987-991.

3. Khoshkrood-Mansoori B, Pourhoseinggholi MA, Safaee A, et al. Irritable bowel syndrome; a population based study. J GastrointestinLiver Dis. 2009; 18(4):413-418.

4. Sorouri M, PourhoseinggholiMA, vahediM,et al. Functional bowel disorders in Iranian population using RomeIII criteria. Saudi J Gastroenterol. 2010; 16(3):154-60.

5. Choi MG and Jung HK. Healthrelated quality of life in functional gastrointestinal disorders in Asia. J NeurogastroenterolMotil. 2011; 17(3): 245-251

6. Folks DG. The interface of psychiatry and irritable bowel syndrome. Curr Psychiatry Rep. 2004; 6(3):210-5.

7. Henningsen P, Herzog W. Irritable bowel syndrome and somatoform disorders. J Psychosom Res. 2008; 64(6):625-9.

8. Drossman DA, Creed FH, Olden KW, Svedlund J, Toner BB, Whitehead WE. Psychosocial aspects of the functional gastrointestinal disorders. Gut. 1999;45(2):1125-30.

9. Whitehead WE, Palsson O, Jones KR. Systematic review of the comorbidity of irritable bowel syndrome with other disorders: what are the causes and implications? Gastroenterology. 2002; 122(4):1140-1156.

10. Roy-Byrne P, Davidson K, Kessler R, Asmundson G, Goodwin $\mathrm{R}$, Kubzansky L et al. Anxiety disorders and comorbid medical illness. FOCUS. 2008; 6:467-485.

11. Farzaneh N, Ghobakhlou M, Dehkordi B, Naderi M, Fadai F. Evaluation of Psychological Aspects Among Subtypes of Irritable Bowel Syndrome. Indian J Psychol. 2012;34(2): 144-148.

12. Muscatello MR, Bruno A, Pandolfo G, Mico U, Stilo S, Scaffidi $\mathrm{M}$, et al. Depression, anxiety and anger in subtypes of irritable bowel syndrome patients. J ClinPsychol Med Settings. 2010; 17(1):64-70.

13. Mertz H, Morgan V, Tanner G, Pickens D, Price R, Shyr Y, et al. Regional cerebral activation in irritable bowel syndrome and control subjects with painful and nonpainful rectal distention. Gastroenterology. 2000;118:842-848.

14. Naliboff BD, Derbyshire SW, Munakata J, Berman S, Mandelkern $\mathrm{M}$, Chang L, et al. Cerebral activation in patients with irritable bowel syndrome and control subjects during rectosigmoid stimulation.Psychosom Med. 2001;63:365-375.

15. Modabbernia MJ, Mansour-Ghanaei F, Imani A, MirsafaMoghaddam SA, Sedigh-Rahimabadi M, Yousefi-Mashhour M, et al. Anxiety-depressive disorders among irritable bowel syndrome patients in Guilan, Iran. BMC Res Notes. 2012; 5: 112.

16. Francis CY, Morris J, Whorwell PJ. The irritable bowel severity scoring system: a simple method of monitoring irritable bowel syndrome and its progress. Aliment PharmacolTher. 1997; 11(2):395-402.

17. Perveen I, Rahman MM, Shaha M, Rahman MM, Hasan MQ. Prevalence of irritable bowel syndrome and functional dyspepsia, overlapping symptoms, and associated factors in a general population of Bangladesh. Indian J Gastroenterol. 2014; 33(3):265-73.

18. Liu L, Xiao Q, Zhang Y, and Yao S. A cross-sectional study of irritable bowel syndrome in nurses in China: prevalence and associated psychological and lifestyle factors. J Zhejiang Univ Sci B. 2014; 15(6).

19. Derogatis L.R \& Melisaratos N. The Brief Symptom Inventory: an introductory report. Psychological Medicine. 1983; 13 (3):595605 .

20. Farzaneh N, GhobaklouM, Moghimi-Dehkordi B, Naderi N, Fadai F. Effects of Demographic Factors, Body Mass Index, Alcohol Drinking and Smoking Habits on Irritable Bowel Syndrome: A Case Control Study. Ann Med Health Sci Res. 2013; 3(3): 391-396.

21. Jerndal P, Ringström G, Agerforz P, Karpefors M, Akkermans LM, Bayati A et al. Gastrointestinal-specific anxiety: an important factor for severity of GI symptoms and quality of life in IBS. NeurogastroenterolMotil. 2010; 22(6).

22. Talley NJ, Dennis EH, Schettler-Duncan VA, Lacy BE, Olden $\mathrm{KW}$, Crowell MD. Overlapping upper and lower gastrointestinal symptoms in irritable bowel syndrome patients with constipation or diarrhea. Am J Gastroenterol. 2003; 98(11):2454-2459.

23. Farbod F, Farzaneh N, Bijan MD, Mehdi G, Nosratollah N. Psychological features in patients with and without irritable bowel syndrome: a case-control study using Symptom Checklist-90Revised. Indian J Psychiatry. 2015; 57(1): 68-72. 